Scientific Journal of Silesian University of Technology. Series Transport Zeszyty Naukowe Politechniki Śląskiej. Seria Transport

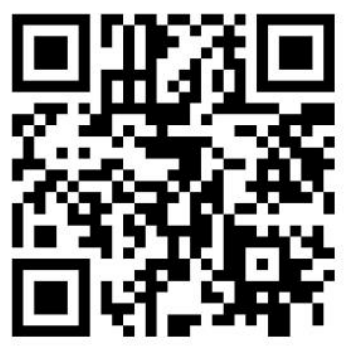

Volume 114

2022

p-ISSN: 0209-3324

e-ISSN: 2450-1549

DOI: https://doi.org/10.20858/sjsutst.2022.114.6

Journal homepage: http://sjsutst.polsl.pl

Article citation information:

Marciano, P., Wheatley, G., Ali, A. Differential designing for FSAE motor sports vehicle JCU. Scientific Journal of Silesian University of Technology. Series Transport. 2022, 114, 67-78. ISSN: 0209-3324. DOI: https://doi.org/10.20858/sjsutst.2022.114.6.

Pieta MARCIANO ${ }^{1}$, Greg WHEATLEY ${ }^{2}$, Ahmed ALI ${ }^{3}$

\title{
DIFFERENTIAL DESIGNING FOR FSAE MOTOR SPORTS VEHICLE JCU
}

Summary. The objective of this work was to design a differential assembly for an FSAE motor sports vehicle. The designed differential system consists of 3 braces made of AISI 1045 steel. The output shafts were made of AISI 4140 steel with hardened splines. These shafts were initially going to drive $94 \mathrm{~mm}$ constant velocity shafts. A $75 \mathrm{~mm}$ tripod joint was used to minimize the weight and cost of the system. The housing was held together with grade 12.8 hex head bolts, and the shafts were bolted onto the tri-pod joints using bolts of grade 8.8 which complies with FSAE rules. The input shaft which acts on the differential itself is made of EN36A steel and is where the drive sprocket is bolted to. All components were modeled using Finite Element Analysis to determine stresses and displacements under operating conditions.

Keywords: torque transition, shaft system, FEA

\footnotetext{
${ }^{1}$ College of Science and Engineering, James Cook University, Townsville QLD 4811. Australia. Email: pieta.marciano@my.jcu.edu.au. ORCID: https://orcid.org/0000-0002-9115-9695

${ }^{2}$ College of Science and Engineering, James Cook University, Townsville QLD 4811. Australia. Email: greg.wheatley@jcu.edu.au. ORCID: https://orcid.org/0000-0001-9416-3908

${ }^{3}$ College of Engineering, King Saud University, Riyadh, Saudi Arabia. Email: jubara66@ hotmail.com. ORCID: https://orcid.org/0000-0001-7490-4545
} 


\section{BACKGROUND AND LITERATURE REVIEW}

The objective of this work is to develop and improve the existing design for the differential of a $600 \mathrm{cc}$ formula car. Differential devices are an integral component of any motor vehicle that allows the driving wheels (either front or rear) to rotate at different speeds when turning. When a vehicle is rounding a corner or traveling in any direction other than exactly straight, the outer wheel of the vehicle is required to travel a larger distance than the inner wheel. To compensate for this difference in distance traveled, a differential allows the outer wheel to travel faster to counteract the disparity in the distance, while in most cases, supplying both wheels with equal torque.

When designing a differential system, the main concerns are cost, weight, and reliability. In addition, the developed differential must comply with all the relevant 2010 FSAE competition guidelines, which are:

(1) The drive train must not leak.

(2) If a chain is used it must have a guard following the appropriate FSAE rules.

(3) All bolts used must have a grade of M8.8 or greater.

(4) The design must be compatible with the purchase parts.

(5) The differential must be compatible with a CBR $600 \mathrm{cc}$ motor.

(6) The driveline must not exceed $15 \mathrm{~kg}$.

(7) The driveline must not exceed an allocated budget of $\$ 5,000$.

(8) The driveline must complete all of the competition without fail.

\subsection{Differential}

There are many different types of differential devices such as:

(1)Locking Differential: the main feature of this differential is the ability for it to be "locked" to give the effect of a common shaft between the wheels. This allows both wheels to turn in unison, and thus, rotate at the same speed, irrespective of the amount of traction identified at each wheel. The benefit of the locking design differential becomes apparent when the surface traction experienced by each wheel differs significantly [1].

(2)Spool Differential: consists of only a pinion and ring gear with a solid center. The solid axle arrangement permits both wheels to travel at the same speed and allows for greater torque where needed at each wheel. A disadvantage of a spool differential is that each wheel travels at the same speed. It is highly economical and is usually employed on vehicles that spend most of their life driving off-road where high traction is essential [2].

(3)Limited slip differential (LSD): works like basic differentials under normal driving conditions, while under abnormal conditions, where one wheel experiences a higher resistance than the other, the torque is appropriately divided between the wheels (with a greater amount of torque applied to the wheel of higher resistance). The most common types of LSD are torque-sensitive differentials (geared, clutch, and cone-based differentials) and speed-sensitive differentials (viscous and clutch pack). A high friction Automatic Torque Biasing (ATB) differential, such as the Torsen differential, provides the same function as a basic limited slip differential, but uses added gear teeth as opposed to added clutches. The disadvantage of a LSD is that if no load is applied at one wheel, then no torque multiplying can occur, thus no extra torque can be applied to the other wheel. This disadvantage can be overcome in some cases through the application of the rear brakes and precision driving [3]. 
The type of differential arrangement employed in any vehicle is dependent upon the driving conditions it is anticipated to experience. For a predominately off-road vehicle, a spool differential or locking differential may be the most appropriate system as it provides increased traction where it is needed most, while a LSD would be more favorable in high performance vehicles, like ours, in anticipation of the event that one wheel suffers traction loss.

\subsection{Torque transition}

Gears are used in a rear axle design as one method of transmitting torque from the motor to the drive shafts. Tooth shaped gears provide a greater area of tooth contact along with greater strength allowing a high amount of torque to be transmitted. Although the downside with this configuration is that the correct adjustment is needed to prevent gear noise, the design is heavy and a custom gear would have to be made to fit.

An alternative method to using gears is using a chain to transmit torque to the different parts that make up the drive train system. This method involves using two sprockets and a bike chain to transmit torque. A greater amount of weight is saved when using this method compared to gears. The disadvantage of this method is the possibility of the chain snapping if too much load is applied.

This method is not often incorporated into formula style race car designs because of the high possibility of slip occurring and breakage/snapping of the belt. This occurs when too much load is applied to the two pulleys and belt that transmit torque from the engine to the drive shafts. The only advantage is the amount of weight that is saved.

\subsection{Differential drive shaft system}

In differential systems involving a rotating housing, the differential is bolted to the housing so that it rotates as the housing does. Connected to the housing is the sprocket which connects to two shafts, the shafts lead from the differential out to the CV joints. Using this method allows each wheel to rotate at different speeds, which reduces tire wear and increases traction. The mass moment of inertia of this system is ideal along with the weight. However, when excessive conditions are applied to this design, the housing could allow for leakage.

Differential and Non-Rotating Housing: This system requires the case to be locked while the differential rotates inside; an output shaft then connects to the sprocket which is required to transmit the torque to the differential. Two hollow shafts are required to complete the drive process and transmit the torque to the two wheels. The ability of the differential to rotate freely reduces the mass moment of inertia; this also reduces the risk of leakage due to the fixed nature of the housing allowing a vent to be incorporated.

\subsection{Motor}

CBR $600 \mathrm{cc}$ : The FSAE guidelines and rules request that an engine no larger than $600 \mathrm{cc}$ be used in supplying the power needed to drive the car. This implies that two $300 \mathrm{cc}$ engines could be incorporated into the design of the car or even more simply one $600 \mathrm{cc}$ engine could be used. The maximum torque the $600 \mathrm{cc}$ engine produced at the wheels of the car was calculated, using the engine specifications, as $1,180 \mathrm{Nm}$, which is equivalent to a total engine capacity of $50 \mathrm{Nm}$. 


\subsection{Existing design}

The differential was a Torsen differential. To comply with the rules of FSAE, the differential must be encased in oil and the unit must not leak. The original unit was designed so that the differential housing rotated with the differential itself. Another problem that comes with having a rotating housing is that the oil plug becomes a rotating unbalanced mass, meaning that it will contribute to vibration in the rear section of the vehicle, which can add stress and limit the life of components such as bearings.

The CV joints assigned to the current design were supplied by Brett Ellacott. These are a bolt-on variety of unknown manufacture. In addition, the condition of the joints is questionable, as one or more of the CV boots are cracked, which means debris may have entered the joint and caused some damage. Ideally, a CV shaft from a road-going vehicle would enable the university to save costs in making custom $\mathrm{CV}$ shafts as these are expensive to fabricate at a custom length. Furthermore, it would also be beneficial to eliminate bolting the CV shafts to intermediate plates with splines; this should reduce weight and eliminate weak areas, and the necessity to balance the extra components to eliminate vibration. The issue with using a predetermined length $\mathrm{CV}$ is that the driveline group will have to work carefully with the suspension group and the group in charge of designing the uprights. The differential housing itself will be the most affected in using a predetermined length $\mathrm{CV}$.

Currently, a 42 teeth chain ring is available for the driveline; however, this is not ideal, as a large top speed is not required for FSAE events. Therefore, a 52 teeth chain ring or greater would be ideal and with the current setup should still be able to reach a speed of up to 200 $\mathrm{km} / \mathrm{hr}$ depending on the gear ratios within the CBR600 gearbox. The chain ring should be easily sourced from a wrecker or motorbike shop. The chain ring was designed to be bolted to the differential housing, rather than using a spline. This must be applied carefully as the shearing of bolts can be an issue. The grade of the bolt must be carefully chosen, grade 8.8 or greater should be used. This will be verified using calculations. Further, as this is mounted to the differential itself, FEA calculations will have to be conducted to verify if the case can handle the loads applied.

For the final mounting location for the differential housing, it is essential to have good communication with the suspension group and the uprights group. Moreover, the final mounting location may be limited by the frame as the size of the chain ring and the size of the rear section of the frame may be an issue as seen below in Figure 6. Similarly, the angle at which the chain can exit the driving sprocket is an issue due to the design of the gearbox. Normally on a motorbike, the chain ring/sprocket is situated a much further distance away from the driving cog allowing a smaller exit angle for the chain. Due to the design limitations, this has to be carefully considered when choosing the size of the chain ring and the location of the differential mount.

\section{DESIGN DECISIONS}

(1) The output torque from the $600 \mathrm{cc}$ CBR motor will be transferred from a 14-tooth sprocket to a 49-tooth sprocket bolted to the housing of the differential using a chain.

(2) The housing of the differential will be stationary and should not leak in accordance with the rules. It will incorporate a vent in which the oil cannot escape as the temperature increases and the oil expands. 
(3) The shaft that transmits from the sprocket will have to be hollow to allow the torque to be transmitted back out of the wheels. This shaft will also need to have a spline connecting it to the differential as well as a connection to the sprocket.

(4) The shafts that connect the differential to the wheels will need splines to fit the differential and connections to the $\mathrm{CV}$ joints.

(5) The housing will require 3 seals to contain any oil leaking.

(6) The differential unit will be mounted inside the housing in 2 ball bearings (single row deep groove ball bearings).

(7) The chain will be tensioned using an adjustable mounting system.

(8) The oil used to fill the housing will be a $75 \mathrm{~W}-90$ gear oil.

(9) The CV joints will be a tripod format from Taylor Racing.

\section{PARTS}

The tripod assembly was selected for the design due to its low cost and weight. The tripod assembly consists of a tripod joint, housing, and boot. Two of these assemblies are required for the attachment to the output shafts. A further two assemblies are required by the rear uprights team which would connect via a half shaft.

A sprocket is similar to a gear in that it has teeth that mesh with a chain, track or other perforated or indented material. A sprocket is more commonly referred to as a profiled wheel and differs from both a gear in that sprockets are never meshed together directly, and from a pulley in that sprockets have teeth and pulleys are smooth. From basic calculations and solid works drawings, the most appropriate sprocket for the differential, when keeping the engine sprocket was a 50-tooth gear. This is a standard gear sizing which means it is easily sourced from companies. A 50-tooth sprocket specified for the rear gives a final drive ratio of 3.2:1. To attach this sprocket to the differential, a flange with $6 \times$ M8.8 bolts with a pitch circle diameter of $80 \mathrm{~mm}$ will be used. To ensure the sprocket can take the loadings and forces applied to it by the various driving conditions of the FSAE competition, it is necessary to look at options to increase the fatigue life of the material used. Flame hardening is widely used in deep hardening for large substrates and is only applicable to steels that have sufficient carbon and alloy content to allow quench hardening. This hardening treatment does not significantly change the dimensions. Flame hardening uses a high intensity oxy-acetylene flame that is applied to the selected region. The temperature is raised high enough to be in the region of Austenite transformation.

The chains function in the driveline system is to transfer power from the engine to the sprocket on the differential. If a maximum load was to occur, to save the engine and the differential unit from unnecessary damage, the chain is required to snap before any of the car's essential components. This would be an important consideration when choosing a relevant chain design. For future design considerations, a new 520 chain should be purchased. The chain has two options, O-ring or non-O-ring. The cost and friction benefits of the non-O-ring chain make the choice easy. The most appropriate chain was sourced to be the D.I.D. 520-ERT due to its strength price and availability. This is a lightweight chain, but its breaking strength of 8470 pounds compares well to a standard 520 pitch O-ring chain with an approximate breaking strength of $9000 \mathrm{lbs}$.

Current differential style was a LSD manufactured by Torsen. This type of differential is simply a torque multiplier that works through the use of friction generated by thrust forces from the internal gearing. It multiplies the torque available from the wheel that is starting to spin-up 
or lose traction and sends that available torque, multiplied by the TBR, to the slower turning wheel with the better traction. The differential itself weighs about $3 \mathrm{~kg}$ and can transmit anywhere up to $5200 \mathrm{Nm}$ of torque. The differential has a torque bias ratio of 3.2:1, however, as the gears wear, this ratio can drop anywhere within 2.6:1. This means that the output of any of the two shafts singularly can never reach $100 \%$ torque. Thus, allowing the torque to be transmitted to the wheels even if one is not in contact with the ground.

A bearing is a device that allows constrained relative motion between two or more parts, typically rotation or linear movement, while a seal prevents leakage or the addition of unwanted material. Bearings may be broadly classified according to the motions they allow and their principle of operation as well as by the directions of applied loads they can handle. Seals simply come in kits that relate to their required task.

Bolted joints are one of the most common elements in construction and machine design. They consist of fasteners that capture and join other parts and are secured with the mating of screw threads. There are two main types of bolted joint designs. In one method, the bolt is tightened to a calculated clamp load, usually by applying a measured torque load. The joint is designed such that the clamp load is never overcome by the forces acting on the joint (and therefore, the joined parts see no relative motion). The bolts used in the differential design must follow the FSAE rules. This infers that a M8 bolt of grade 8.8 or higher must be used to comply with the rules. Presently, M8 bolts are used to mount the differential housing into the car and seal the differential housing.

Venting and Sealing: When designing the differential, it must not leak, as this would fail according to the FSAE rules. To avoid this, a stationary housing with the differential rotating inside was used. It was assumed that if the housing was still the oil would not have a chance to slosh around as much and pool in places where its expanding could cause a leak. With the housing stationary, a breather is allowed to be positioned on top, allowing increased pressure from the oil expanding to be dispersed. Sealing is also an important consideration when trying to avoid oil leaking. The seals are added to the joining of the housing and between the joining to stop the oil from working its way into places like the flange.

\section{DESIGN LOADING}

When designing the input shaft, it was necessary to consider factors such as friction, acceleration and torque. These factors are important when considering the calculation of forces as if the maximum amount of torque the engine can supply was transmitted to the tires, they would slip or skid. It can be seen that when a car is accelerating, there is a transfer of weight to the rear wheels of the car, this increases the torque required to skid the tires. Currently, the car is estimated to weigh around $400 \mathrm{~kg}$, with $200 \mathrm{~kg}$ of this lying at the rear axle. Considering these weights, the center of gravity is noted to be halfway between the centers of the wheels. The height of the center of gravity is to be $300 \mathrm{~mm}$ and the length from the centers of the tires is to be $1.72 \mathrm{~m}$. The force acting due to acceleration through the center of gravity could be calculated as:

Drag force

$$
W=W_{\text {Front }}+W_{\text {Back }}
$$

$$
F_{\text {drag }}=W_{\text {Front }} * \mu+W_{\text {Back }} * \mu
$$

Moment

$$
\left(F_{\text {drag }} * h\right)+\left(W_{\text {back }} * L\right)-\left(R_{\text {back }} * L\right)=0
$$


Accelerating torque

$$
T_{\text {accelerating }}=R_{\text {back }} * \mu * r * K
$$

Maximum normal

$$
\sigma=\frac{M_{y}}{I_{x}} * K_{\text {Bending }}
$$

Maximum shear

stress

$$
\tau=\frac{T_{r}}{I_{p}} \cdot K_{\text {Torsion }}+\frac{V}{A}
$$

Fatigue life

$$
N=\left(\frac{\sigma_{\max }}{a}\right)^{\frac{1}{b}}
$$

Fatigue constants

$$
a=\frac{\left(f * S_{u t}\right)}{s_{e}} \text { and } b=-\frac{1}{3} \log \left(\frac{f * s_{u t}}{S_{e}}\right)
$$

Where:

$\mu=\quad$ Coefficient of friction of the tires $=0.9$ [2]

$r=\quad$ Radius of the tires $=250 \mathrm{~mm} \mathrm{[4]}$

$K=\quad$ Shock loading factor $=1.4[5]$

Using equations (1)-(8), the drag force, maximum weight acting on the rear wheels due to acceleration, accelerating torque, maximum normal and shear stresses, and fatigue life were calculated, both for the input and output shafts, and tabulated in Bląd! Nie można odnaleźć źródła odwołania..

Tab. 1.

Summary of the design loading

\begin{tabular}{|l|c|c|}
\hline \multicolumn{1}{|c|}{ Parameter } & Input shaft & Output shaft \\
\hline Drag force, $\mathrm{N}$ & 360 & - \\
\hline Max. weight on the rear wheels, N & 262.79 & - \\
\hline Accelerating torque, Nm & 85 & 540 \\
\hline Maximum normal stress, MPa & 294 & 225 \\
\hline Maximum shear stress, MPa & 257 & 225 \\
\hline Selected material & EN36A & AISI 4140 \\
\hline Fatigue life, cycles & $1,362,200$ & $\underline{\mathbf{3 4 , 6 4 8 , 0 0 0 , 0 0 0}}$ \\
\hline
\end{tabular}

\section{FINITE ELEMENT ANALYSIS}

Finite Element Analysis was conducted for all major components of the differential assembly. This was done to identify areas of stress concentration and determine if the design will fail. Below is the FEA, conducted in SolidWorks, of the left and right output shafts. The torques applied to the left and right output shafts were $540 \mathrm{Nm}$ and $85 \mathrm{Nm}$, respectively (Bląd! Nie można odnaleźć źródła odwołania.). A very fine mesh was applied in areas of high stress concentration. 

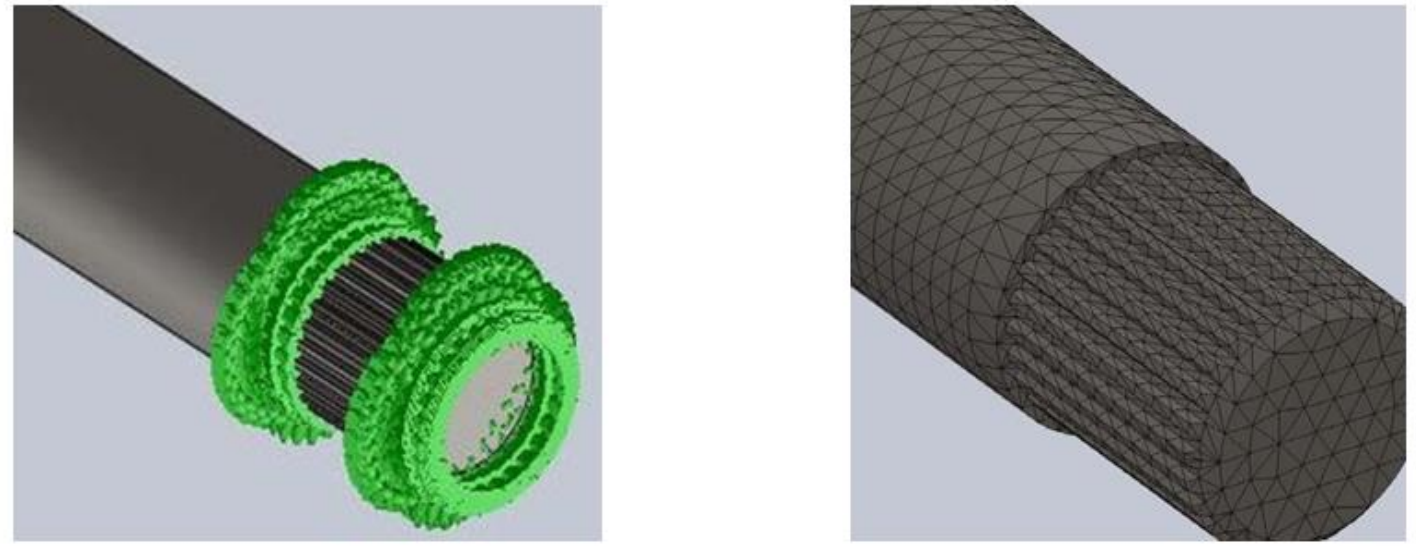

Fig. 1. Mesh of the left output shaft
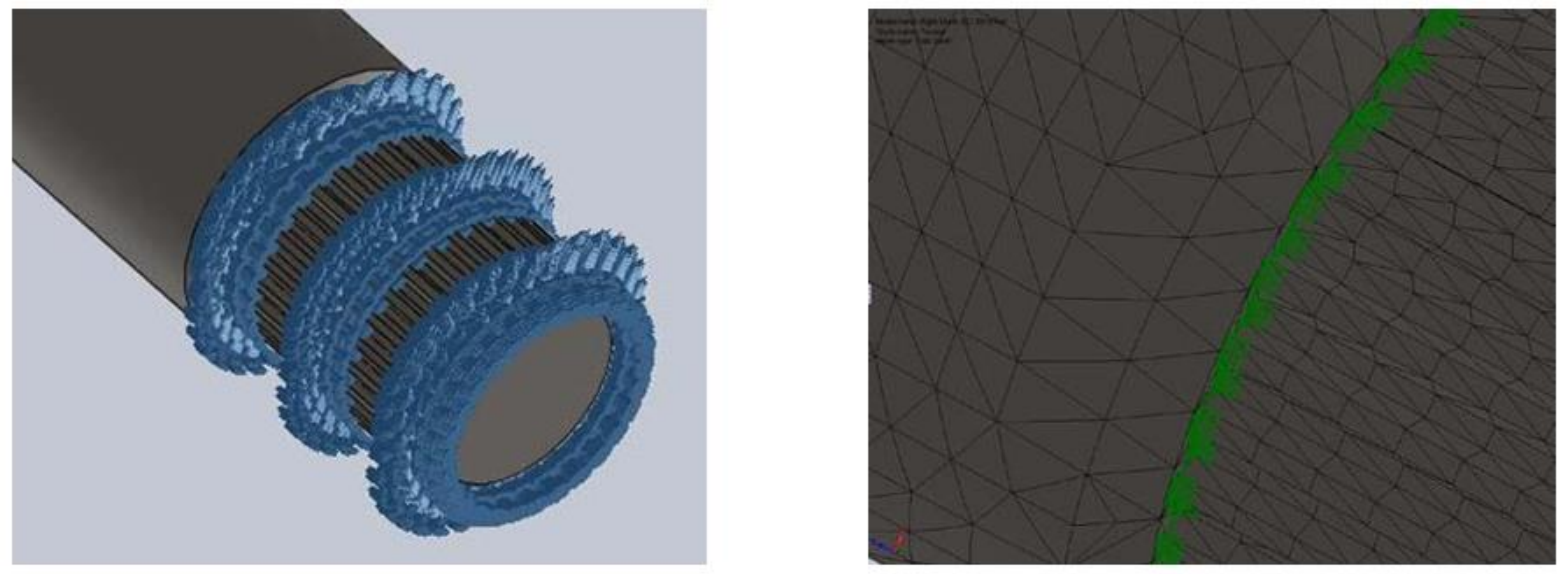

Fig. 2. Mesh of the right output shaft
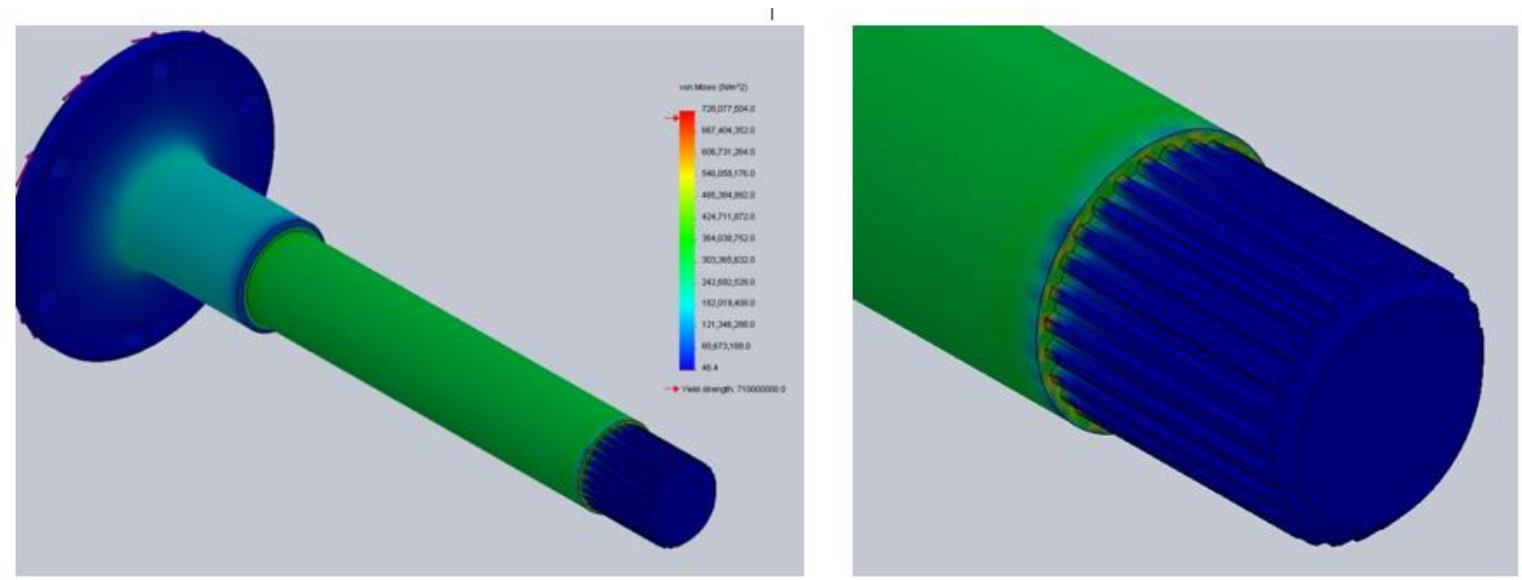

Fig. 3. von Mises stress distribution for the left output shaft 

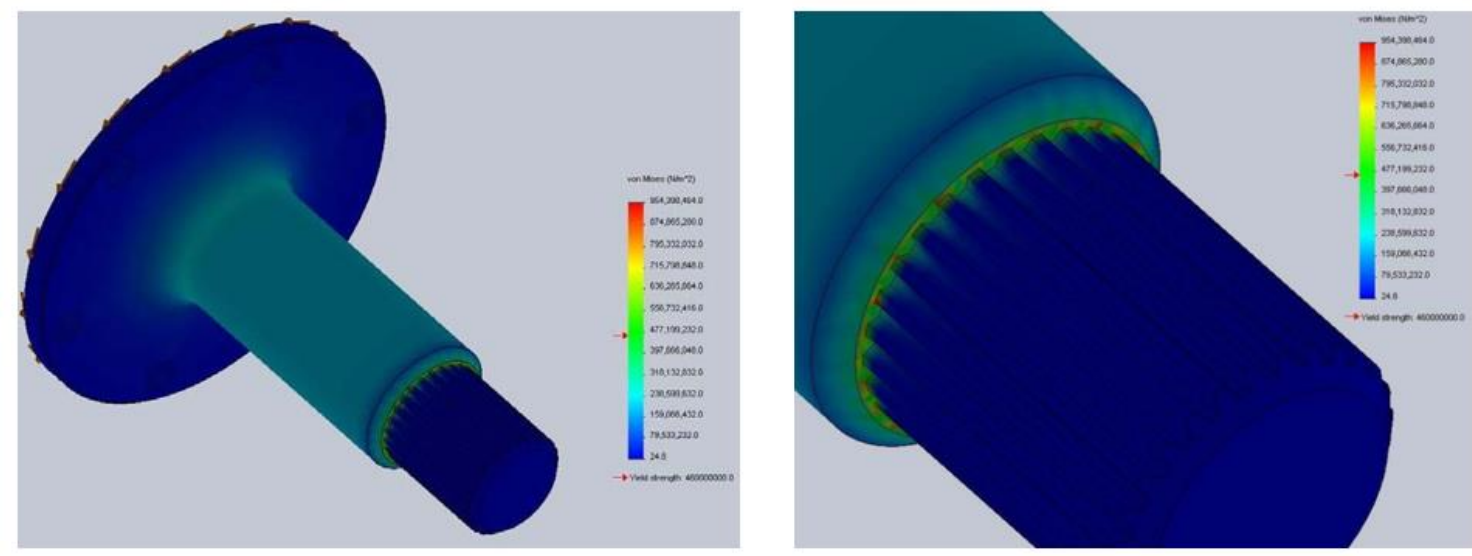

Fig. 4. von Mises stress distribution for the right output shaft
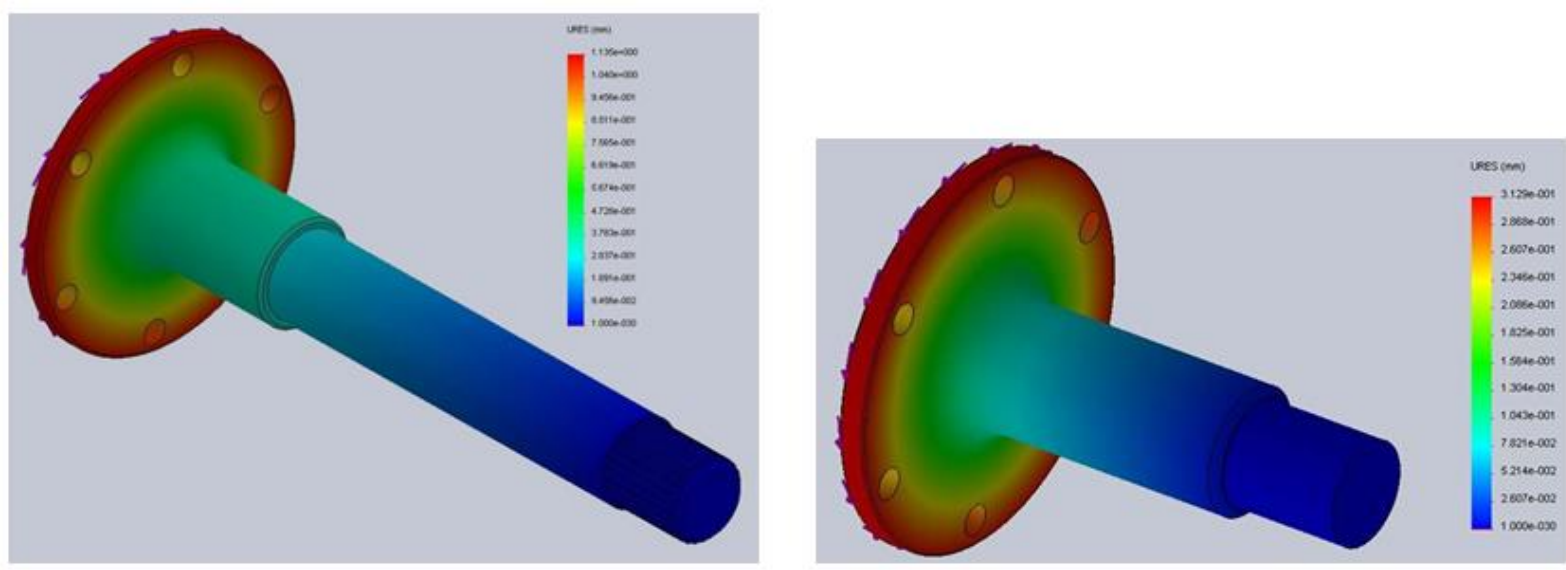

Fig. 5. Displacement distribution for the left (on the left) and right (on the right) output shaft

From Fig. 3 and Fig. 4 above, it is seen that yielding occurs in localized areas, which means failure of the overall model should not occur. Under operation, these areas of yielding will work harden (strain harden). In addition, the largest von Mises Stresses that occurred were below the yield strength of the AISI 4140 strain hardened material of $900 \mathrm{MPa}$.

The input shaft is made of EN36A. The maximum stress, Fig. 6(a), occurs at the stress concentration areas below the yield strength.

The results of the left, middle, and right braces assembly showed that the design will not yield Fig. 7).

A summary of the results of the FEA analysis is tabulated in Tab. 2. All the components showed a good failure resistance. 


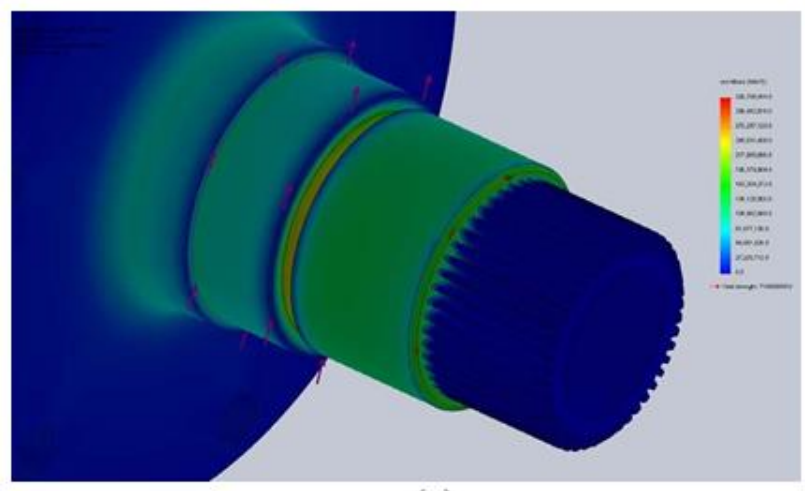

(a)

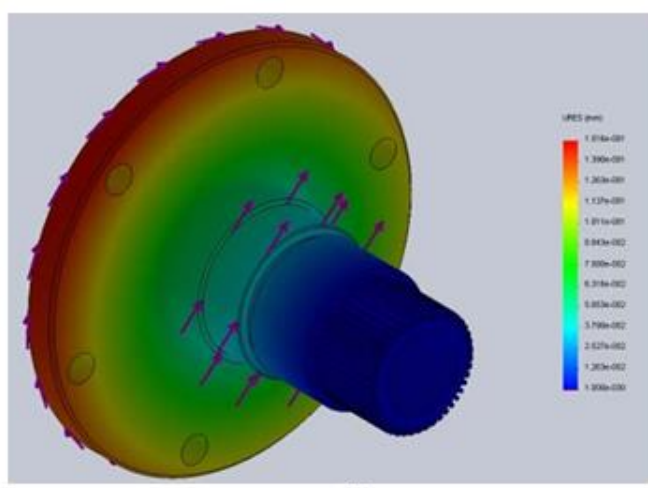

(b)

Fig. 6. (a) von Mises stress and (b) displacement distribution for the input shaft

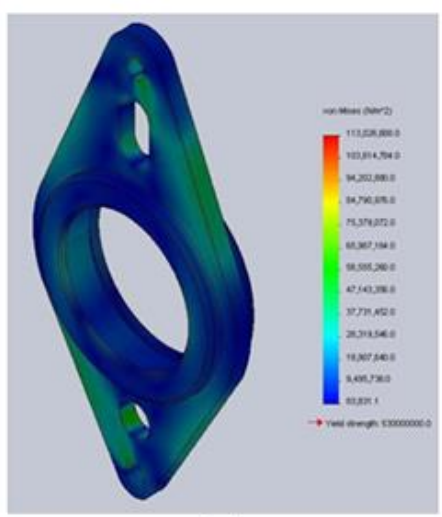

(a)

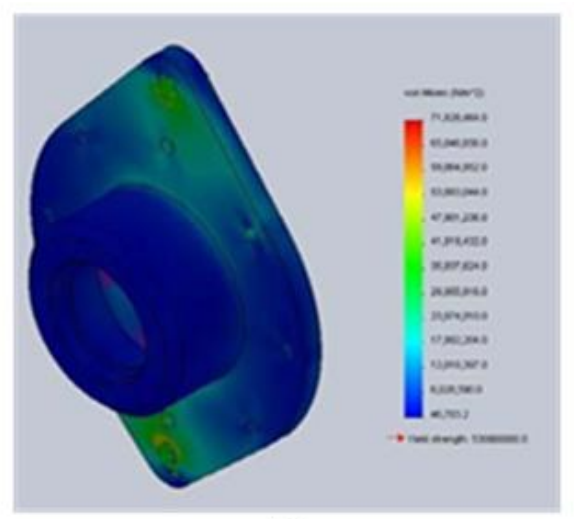

(b)

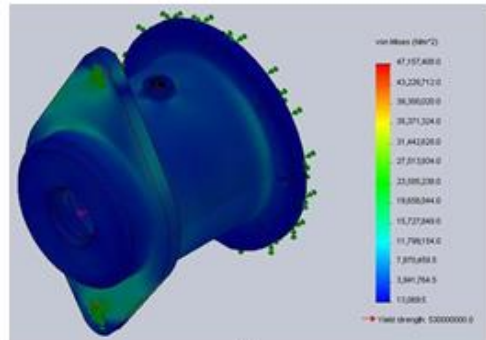

(c)

Fig. 7. von Mises stress distribution for (a) left, (b) middle, and (c) right braces

Tab. 2.

Summary of FEA results

\begin{tabular}{|c|c|c|c|c|}
\hline Part & Material & $\begin{array}{c}\text { Yield } \\
\text { strength, } \\
\text { MPa }\end{array}$ & $\begin{array}{c}\text { Displacement, } \\
\text { mm }\end{array}$ & $\begin{array}{c}\text { von Mises } \\
\text { stress, MPa }\end{array}$ \\
\hline Right output shaft & AISI 4140 & \multirow{2}{*}{900} & 0.3129 & \\
\hline Left output shaft & Mild Steel & & 0.1135 & 728.1 \\
\hline Input Shaft & $\begin{array}{c}\text { EN36A } \\
\text { Hardened } \\
\text { Steel }\end{array}$ & 540 & 0.1616 & 326.7 \\
\hline Left brace & \multirow{3}{*}{$\begin{array}{l}\text { AISI } 1045 \\
\text { Mild Steel }\end{array}$} & \multirow{3}{*}{560} & - & 113 \\
\hline Middle brace & & & - & 72 \\
\hline Right brace & & & - & 47 \\
\hline
\end{tabular}




\section{SUMMARY}

In designing the differential, we aimed to incorporate low cost, lightweight and reliability while adhering to all the physical constraints and regulations defined by the Formula SAE governing body. However, these factors were achieved without compromising concepts like speed, braking and acceleration.

The design of the differential was analyzed with the available tools (FEA). It was found that the Formula SAE differential appears to meet the stated goals of reduced weight, better integration with the car, and increased robustness over previous designs.

A lot of work was conducted to ensure the reliability of the project and its findings; however, there is room for improvement. Improvement is possible in areas such as the Finite Element Analysis section where it is admittedly not very thorough as certain loads were ignored or roughly estimated. Along with this, further analysis such as fatigue and motion analysis would be beneficial. Limitations aside, it is hoped that this design will serve as a starting point for further optimization of the differential. Determining the "best" design solution is always a compromise of strength, functionality, manufacturability, cost, and other factors. While this differential offers much strength in these areas, it is important to note that a racecar is never complete and better alternatives or improvements always exist.

\section{References}

1. Wikipedia. „Locking differential”. Available at: https://en.wikipedia.org/wiki/Locking_differential\#: :text=A\%20locking\%20differential \%20is\%20designed,available\%20to\%20either\%20wheel\%20individually.

2. Budynas Richard, J. Keith Nisbett. 2008. Shigley's Mechanical Engineering Design. London: McGraw-Hill, ISBN: 978-0-0731-2193-2.

3. Stockel Martin, James Duffy. 1998. Automotive Mechanics: Fundamentals. City: Gregory's Automotive, Haynes Manuals Inc. ISBN: 978-0-8556-6626-2.

4. Engineers handbook. "Friction Coefficient". Available at: http://www.engineershandbook.com/tables/frictioncoefficient.htm.

5. Mott Robert. 2006. Machine Elements in Mechanical Design. City: Pearson. ISBN: 978-9-8106-8251-4.

6. Juvinall Robert, Kurt Marshek. 2000. Fundamentals of Machine Component Design, City: John Wiley and Sons. ISBN: 978-1-119-38290-4.

7. Pritchard Philip, John W. Mitchell. 1998. Introduction to Fluid Mechanics. City: John Wiley and Sons. ISBN: ES8-1-118-91265-2.

8. SKF Sealing Solutions. „Chicago Rawhide Handbook of Seals”. Available at http://www2.chicago-rawhide.com/catalogpdf.htm.

9. NTN Americas. „NTN Radial Ball Bearings”. Available at: http://www.ntnamerica.com/Engineering/PDFs/A 1000/A 1000_Radial.pdf.

10. Callister William, David Rethwisch. 1997. Material Science and Engineering: An Introduction. City: John Wiley \& Sons. ISBN: 978-1-119-40549-8.

11. Hosking A., M. Harris. 1997. Applied Mechanical Design. Victoria: Forest Hill. ISBN: 0959375805.

12. South David, Jon Mancuso. 1994. Mechanical Power Transmission Components. New York: Marcel Dekker. 
13. Mott Robert. 2004. Machine Elements in Mechanical design. Sydney: Pearson. ISBN: 978-0-1306-1885-6.

Received 19.10.2021; accepted in revised form 09.12.2021

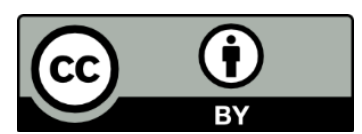

Scientific Journal of Silesian University of Technology. Series Transport is licensed under a Creative Commons Attribution 4.0 International License 